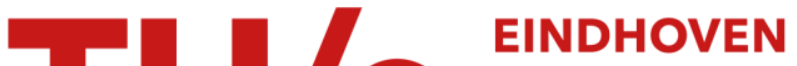 UNIVERSITY OF TECHNOLOGY
}

\section{Optimization of multibody systems using approximation concepts}

Citation for published version (APA):

Etman, L. F. P., Campen, van, D. H., \& Schoofs, A. J. G. (1996). Optimization of multibody systems using approximation concepts. In D. Bestle, \& W. Schielen (Eds.), IUTAM symposium on optimization of mechanical systems : proceedings of the IUTAM symposium, held in Stuttgart, Germany, 26-31 March 1995 (pp. 81-88). (Solid Mechanics and its Applications; Vol. 43). Kluwer Academic Publishers.

Document status and date:

Published: 01/01/1996

\section{Document Version:}

Publisher's PDF, also known as Version of Record (includes final page, issue and volume numbers)

\section{Please check the document version of this publication:}

- A submitted manuscript is the version of the article upon submission and before peer-review. There can be important differences between the submitted version and the official published version of record. People interested in the research are advised to contact the author for the final version of the publication, or visit the $\mathrm{DOI}$ to the publisher's website.

- The final author version and the galley proof are versions of the publication after peer review.

- The final published version features the final layout of the paper including the volume, issue and page numbers.

Link to publication

\section{General rights}

Copyright and moral rights for the publications made accessible in the public portal are retained by the authors and/or other copyright owners and it is a condition of accessing publications that users recognise and abide by the legal requirements associated with these rights.

- Users may download and print one copy of any publication from the public portal for the purpose of private study or research.

- You may not further distribute the material or use it for any profit-making activity or commercial gain

- You may freely distribute the URL identifying the publication in the public portal.

If the publication is distributed under the terms of Article $25 \mathrm{fa}$ of the Dutch Copyright Act, indicated by the "Taverne" license above, please follow below link for the End User Agreement:

www.tue.nl/taverne

Take down policy

If you believe that this document breaches copyright please contact us at:

openaccess@tue.nl

providing details and we will investigate your claim. 


\title{
OPTIMIZATION OF MULTIBODY SYSTEMS USING
}

\section{APPROXIMATION CONCEPTS}

\author{
L.F.P. ETMAN, D.H. VAN CAMPEN AND A.J.G. SCHOOFS \\ Department of Mechanical Engineering \\ Eindhoven University of Technology \\ P.O. Box 513 Eindhoven, The Netherlands
}

\begin{abstract}
.
Sequential approximate optimization is used to solve multibody optimum design problems. The transient optimization problem is formulated such that approximation concepts can be incorporated. Two multibody design examples illustrate the effectiveness of the approach.
\end{abstract}

\section{Introduction}

Optimum design of multibody systems is characterized by a specific kind of optimization problem. Generally, an optimization problem is formulated to determine the design variable values that will minimize an objective function subject to constraints. For multibody systems, the objective function and constraints are usually time dependent, which complicates the standard problem formulation. Additionally, for many engineering applications, multibody analysis routines are used to calculate the kinematic and dynamic behavior of the mechanical design. As a result, most objective function and constraint values follow from the numerical analysis. Therefore, to solve the optimization problem, the multibody code has to be coupled with a mathematical programming algorithm. Such a coupling may be difficult to implement and can lead to high computational costs.

Numerical design optimization tools have been mainly developed in the field of finite element structural analysis. Many tools use a suitable approximation concept as interface between analysis software and optimizer. Such an interface avoids programming difficulties, and is computationally more convenient than a direct coupling (Haftka and Gürdal, 1992). The basic 
idea is to separate the numerical analysis and optimization. This is established by building an explicitly known approximate optimization problem that can be easily handled by the optimizer.

Local function approximations are the most popular approximations used in optimization (Barthelemy and Haftka, 1993). Large numbers of design variables and constraints can be handled without great difficulty. Moreover, in many cases, design sensitivities can be obtained at reduced computational costs compared with finite difference sensitivity analysis. Local approximations of objective function and constraints are based on function values and derivative values with respect to the design variables in a single point of the design space. Since the approximations have a limited region of validity, a sequence of approximate optimization cycles has to be performed to reach the optimum solution.

Approximate optimization strategies can also be effectively applied to the design optimization of multibody systems. To illustrate this, an optimization tool has been developed based upon a local approximation concept. It has been coupled with the multibody analysis code MECANO (Samtech, 1994). Sensitivities have been calculated by finite differences. The effectiveness of the approach is demonstrated. Suitable intermediate design variables and responses are introduced with the aim to improve the approximations and the efficiency of the optimization process.

\section{Optimization problem formulation}

Within the time interval $t \in[0, T]$, the transient optimization problem is formulated as follows: find the set of design variable values $\mathbf{x} \in \Re^{n}$ that will minimize the objective function:

$$
F(\mathbf{x})=F\left(r_{j}(\mathbf{x}, t), \mathbf{x}\right) \quad \begin{aligned}
& t \in[0, T] \\
& j=1, \ldots, n_{r}
\end{aligned}
$$

subject to the constraints:

$$
\begin{array}{ll}
g_{h}(\mathbf{x}, t)=g_{h}\left(r_{j}(\mathbf{x}, t), \mathbf{x}\right) \leq c_{h} \quad & \forall t \in[0, T] \\
& j=1, \ldots, n_{r} \\
& h=1, \ldots, m
\end{array}
$$

within the design space:

$$
x_{k}^{l} \leq x_{k} \leq x_{k}^{u} \quad k=1, \ldots, n
$$

The scalar $x_{k}$ is the $k$-th element of the design vector $\mathbf{x}$. The set of $n_{r}$ functions $r_{j}(\mathbf{x}, t)$ represents the responses calculated by the multibody code. 
The aforementioned formulation covers several different types of optimization problems that may occur for multibody systems. Most constraints will depend on the response values, although there is no restriction at all for constraints depending on design variables only. Response based constraints can be directly related to the response functions, such as displacements or bending stresses bounded to a maximum value. Other constraints may depend on a response at one specific time point, or be an integral function of a response on a certain time interval. Time point and integral type functions are applicable to the objective function as well.

If a response function $r(\mathbf{x}, t)$ directly determines the corresponding constraint value, a time dependent constraint follows:

$$
g(\mathbf{x}, t) \leq c \quad \forall t \in[0, T]
$$

which must be satisfied during the entire simulation time. This time dependency has to be removed to reach an optimization problem that can be solved by a nonlinear programming algorithm. The most straightforward way is to discretize the time interval into $n_{t}$ time points. Then, the original constraint is replaced by $n_{t}$ constraints:

$$
g_{i}\left(\mathbf{x}, t_{i}\right) \leq c \quad i=i, \ldots, n_{t}
$$

The time point distribution has to be dense enough to avoid too large constraint violations. This increases the number of constraints significantly.

Several equivalent constraint formulations have been proposed to remove time dependency without increasing the number of constraints. Generally, they can be written as an integral function of $g(x, t)$ (Haftka and Gürdal, 1992). However, these constraints may suffer from a strong nonlinear behavior, non-differentiability, or even loss of information of the original constraint. Therefore, Hsieh and Arora (1984) took into account only the 'worst' time point constraints, i.e. all local maxima of the constraint functions.

\section{Sequential approximate optimization}

The optimization problem defined in the previous section is replaced by a sequence of explicitly known optimization problems using a local approximation concept. Vanderplaats (1993) described the basic program structure of the sequential approximate optimization process for finite element structural analysis. This structure is the same for multibody analysis.

Sequential approximate optimization starts with the analysis of the initially proposed design, followed by an evaluation of all constraint functions. Approximation models are generated for the critical and potentially critical 
constraints based upon analysis and design sensitivity data. The approximate optimization problem is built and the region of validity is bounded by so-called move limits. Within this search subregion, the approximate problem is solved by the optimizer. At the calculated optimum design, a new design cycle is started. This process is repeated until convergence.

The most simple approximation is a first-order Taylor series approximation of objective function and constraints. More fundamental implicit functions however are the responses $r_{j}(\mathbf{x}, t)$. Given a set of response values, objective function and constraint values can usually be easily obtained. So the response functions can be approximated instead of the objective function and constraints. This leads to the well-known intermediate response variables. From the design variable point of view, intermediate design variables $\mathbf{x}^{I}(\mathbf{x})$ can be formulated as well. The basic idea is the same: explicit nonlinear functional behavior can be used to improve the approximations, and thus the efficiency and reliability of the optimization process.

We define the approximate optimization problem of a particular cycle as: minimize the approximate objective function:

$$
\tilde{F}(\mathbf{x})=F\left(\tilde{r}_{j i}\left(\mathbf{x}_{j}^{I}(\mathbf{x}), t_{i}\right), \mathbf{x}\right) \quad \begin{aligned}
& i=1, \ldots, n_{t} \\
& j=1, \ldots, n_{r}
\end{aligned}
$$

subject to the approximate active and potentially active constraints:

$$
\begin{aligned}
& \tilde{g}_{h}(\mathbf{x})=g_{h}\left(\tilde{r}_{j i}\left(\mathbf{x}_{j}^{I}(\mathbf{x}), t_{i}\right), \mathbf{x}\right) \leq c_{h} \quad i=1, \ldots, n_{t} \\
& j=1, \ldots, n_{r} \\
& h=1, \ldots, m
\end{aligned}
$$

within the search subregion around the cycle start design $\mathbf{x}_{0}$ :

$$
x_{0 k}^{l}-\alpha_{k} \leq x_{k} \leq x_{0 k}^{u}+\alpha_{k} \quad k=1, \ldots, n
$$

It is assumed that the response functions $r_{j}(\mathbf{x}, t)$ are calculated at a set of $n_{t}$ discrete time points: $r_{j i}\left(\mathbf{x}, t_{i}\right)$. Objective function and constraints follow from these discrete response values according to the selected type of functions. Responses $r_{j i}\left(\mathbf{x}, t_{i}\right)$ are linearly approximated at $\mathbf{x}_{0}$ with respect to the intermediate design variables:

$$
\tilde{r}_{j i}\left(\mathbf{x}_{j}^{I}, t_{i}\right)=r_{j i}\left(\mathbf{x}_{0 j}^{I}, t_{i}\right)+\sum_{k=1}^{n}\left(x_{k j}^{I}-x_{0 k j}^{I}\right)\left(\frac{\partial r_{j i}}{\partial x_{k j}^{I}}\right)_{\mathbf{x}_{0 j}^{I}}
$$

Every response may have its own intermediate design variables $\mathbf{x}_{j}^{I}(\mathbf{x})$.

The number of responses $r_{j i}\left(\mathbf{x}, t_{i}\right)$ to be approximated is highly influenced by the optimization problem formulation. Suppose a constraint is 
active that is an integral function of a response: $g(\mathbf{x})=\int r(\mathbf{x}, t) d t$. Then, all discrete responses $r_{i}\left(\mathbf{x}, t_{i}\right)$ have to be approximated. However, for time point constraints $g_{i}\left(\mathbf{x}, t_{i}\right)$, a large amount of the constraints can be deleted. All constraints can be removed whose constraint value at $\mathbf{x}_{0}$ is smaller than e.g. $70 \%$ of the constraint bound. Additionally, for every local maximum of the constraint $g(\mathbf{x}, t)$, only a few time point constraints $g_{i}\left(\mathbf{x}, t_{i}\right)$ near the maximum have to be retained. This combines the worst time points of Hsieh and Arora (1984), and the constraint deletion of Vanderplaats (1993).

Constraint deletion gives the opportunity to reduce the costs of the sensitivity analysis. Gradients have to be calculated only for a limited set of constraints. For time point constraints this means that the multibody analysis code should be able to calculate gradients just at those time points for which the constraints remain in the set of active and potentially active constraints.

Usually, a local approximation concept requires an appropriate move limit strategy to ensure a good convergence of the optimization process. In this paper we adopt the move limit strategy described in Etman et al. (1994). So, move limits $\alpha_{k}$ are calculated from the absolute value of the design variable values $x_{0 k}$, the maximum approximation error of the previous cycle, and the convergence behavior.

\section{Test problems}

\subsection{DESIGN OF A VEHICLE SUSPENSION SYSTEM}

A five degree of freedom vehicle suspension system, shown in Figure 1, is designed to have an optimal response to road undulation 'Profile No. 1' for a travelling speed of $11.4 \mathrm{~ms}^{-1}$ (Haug and Arora, 1979). Spring coefficients $k_{1}, k_{2}$ and $k_{3}$, and damper coefficients $c_{1}, c_{2}$, and $c_{3}$ have to be determined such that the maximum absolute acceleration of the driver's seat $\left|\ddot{z}_{1}\right|$ is minimized. Constraints are the maximum relative displacements between: chassis and drivers seat, chassis and front and rear wheels, and road surface and front and rear wheels. Every constraint is replaced by 600 time point constraints equally spaced on the time interval of 0 to $3 \mathrm{~s}$. The constraints depend linearly on the responses $\ddot{z}_{1}, z_{1}, z_{2}, z_{3}, z_{4}$, and $z_{5}$. Therefore, a sequence of linear programming problems follows if no intermediate design variables are introduced.

Table 1 shows the convergence behavior of the approximate optimization process. For every design cycle, the maximum approximation error $\left(\max e_{h}\right)$, the maximum constraint violation $\left(\max v_{h}\right)$ and the objective function value $(F)$ are tabulated. Additionally, the number of time points is given at which active and potentially active constraints occur $\left(n_{t}^{a}\right)$, as well as the maximum design variable change $\left(\max \Delta x_{k}\right)$. 


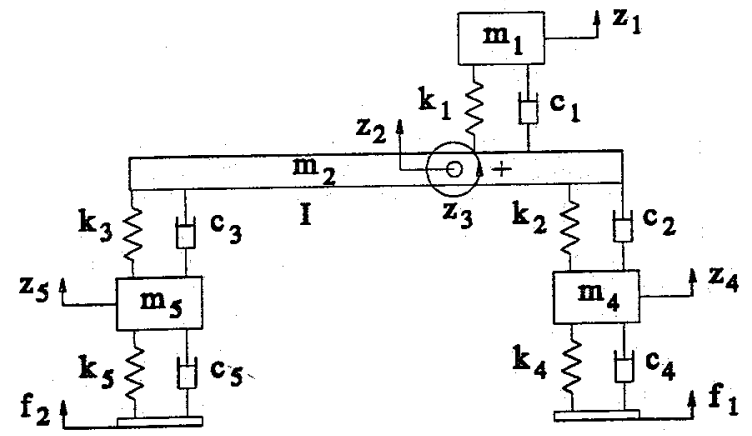

Figure 1. Five degree of freedom vehicle model.

TABLE 1. Optimization history of the vehicle model.

\begin{tabular}{cccccc}
\hline Cycle & $\begin{array}{c}\max \Delta x_{k} \\
{[\%]}\end{array}$ & $n_{t}^{a}$ & $\begin{array}{c}\max e_{h} \\
{[\%]}\end{array}$ & $\begin{array}{c}\max v_{h} \\
{[\%]}\end{array}$ & $\begin{array}{c}F \\
{\left[\mathrm{~ms}^{-2}\right]}\end{array}$ \\
\hline 0 & & & & 51.0 & 8.43 \\
1 & 15.0 & 26 & 23.3 & 35.5 & 7.73 \\
2 & 15.0 & 37 & 19.0 & 20.1 & 7.39 \\
3 & 15.0 & 37 & 20.4 & 5.62 & 7.37 \\
4 & 15.0 & 39 & 3.40 & 0.612 & 7.22 \\
5 & 20.0 & 27 & 4.76 & 1.24 & 6.99 \\
6 & 26.7 & 30 & 7.39 & 0.968 & 6.81 \\
7 & 35.6 & 20 & 3.84 & 0.808 & 6.69 \\
8 & 36.1 & 16 & 3.06 & 0.511 & 6.54 \\
9 & 5.03 & 19 & 0.515 & -0.107 & 6.48 \\
10 & 0.391 & 19 & 0.0219 & 0.00138 & 6.47 \\
\hline
\end{tabular}

The optimum vehicle design was obtained within ten design cycles, starting from the infeasible initial design of Haug and Arora (1979). The final maximum acceleration and the active constraints correspond with Haug and Arora (1979), though the optimum design we found differs for $k_{3}$ and $c_{1}$ : $k_{3}=35.0 \mathrm{kNm}^{-1}$ and $c_{1}=4.05 \mathrm{kNsm}^{-1}$, instead of $k_{3}=42.4 \mathrm{kNm}^{-1}$ and $c_{1}=2.26 \mathrm{kNsm}^{-1}$. This is probably caused by the different optimization problem formulation. Deviations with Etman et al. (1994) are explained by the more dense time discretization. Approximation models were built at 19 to 39 of the 600 time points. During the first three cycles the constraints were relaxed to obtain a feasible solution of the approximate optimization problem. Move limits were active for the first eight cycles. 


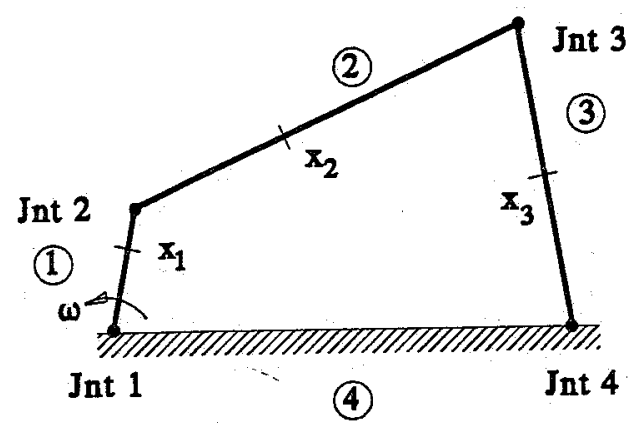

Figure 2. Stress constrained four-bar mechanism.

\subsection{STRESS CONSTRAINED DESIGN OF A FOUR-BAR MECHANISM}

Figure 2 shows a four-bar mechanism that consists of three flexible links, connected to each other and the ground by revolute joints. The three mobile links have a circular cross section, an elasticity modulus of $6.89510^{10} \mathrm{~Pa}$, and a mass density of $2757 \mathrm{kgm}^{-3}$. The lengths of the bars are $l_{1}=$ $0.3048 \mathrm{~m}, l_{2}=0.9144 \mathrm{~m}, l_{3}=0.762 \mathrm{~m}$, and $l_{4}=0.9144 \mathrm{~m}$, respectively. The input crank of the mechanism rotates at a constant angular velocity of $10 \pi \mathrm{rads}^{-1}$. Due to the motion, bending stresses occur in the mobile links. The optimum design problem is now to minimize the mass of the mechanism by varying the cross sectional areas, with the bending stresses constrained to a maximum of $\sigma_{a}=2.75810^{7} \mathrm{~Pa}$.

Each link is modeled by six beam elements. MECANO computed the bending moments $M_{k}^{p}$ in every $p$-th node of link $k$ as a function of time. Stresses can then be calculated from:

$$
\sigma_{k}^{p}=\frac{4 \sqrt{\pi}}{A_{k}^{3 / 2}} M_{k}^{p}
$$

with $A_{k}$ the cross sectional area of body $k$. The bending moments were treated as intermediate response variables. Sohoni and Haug (1982) defined the cross sectional areas $A_{k}$ as design variables. We selected the diameters $d_{k}$ instead, and used the cross sectional areas as intermediate design variables. A time interval of 0.3 to $0.5 s$ is considered, discretized into 201 time points. This exactly covers one period of steady state motion.

A good convergence behavior was found starting from the initial design $d_{1,2,3}=357 \mathrm{~mm}$, with a maximum of 21 time points remaining in the active set. The optimum design is given in Table 2 . The constraint violation, maximum approximation error and objective function accuracy were smaller than $0.1 \%$. The final objective function value reported in Sohoni 
TABLE 2. Optimization of the stress constrained four-bar mechanism.

\begin{tabular}{lcccccc}
\hline Reference & \multicolumn{3}{c}{ Optimum design } & No. & Time & $F$ \\
& \multicolumn{1}{c}{$d_{1}[\mathrm{~mm}]$} & $d_{2}[\mathrm{~mm}]$ & $d_{3}[\mathrm{~mm}]$ & cycles & points & {$[\mathrm{kg}]$} \\
\hline This paper & 37.3 & 23.6 & 19.8 & 13 & $0-21$ & 2.67 \\
Sohoni and Haug (1982) & 36.2 & 28.1 & 12.2 & & & 2.69 \\
\hline
\end{tabular}

and Haug (1982) is approximately the same. Deviations with respect to the design variable values are probably caused by the different method of stress analysis. The use of bending moments as intermediate response variables directly follows from equation (10). However, it is not clear yet which intermediate design variables correspond best with these bending moments. Maybe other intermediate design variables can be found that give a faster convergence than the cross sectional areas we used here.

\section{Conclusion}

Approximation concepts can be effectively used for the design optimization of multibody systems. The two examples demonstrate the effectiveness of separating the analysis and optimization routines. Time dependency can be removed by means of time discretization. The increase of the number of constraints is limited by only approximating the worst critical and potentially critical time point constraints. As a result, gradients are required only at a fraction of all time points. This gives the opportunity to reduce the costs of the design sensitivity analysis.

\section{References}

Barthelemy, J.-F.M. and Haftka, R.T. (1993) Approximation concepts for optimum structural design - a review, Structural Optimization, 5, pp. 129-144.

Etman, L.F.P., Thijssen, E.J.R.W., Schoofs, A.J.G. and Van Campen, D.H. (1994) Optimization of multibody systems using sequential linear programming, in B.J. Gilmore, D.A. Hoeltzel, D. Dutta and H.A. Eschenauer (eds.), ASME Advances in Design Automation, DE 69-2, pp. 525-530.

Haftka, R.T. and Gürdal, Z. (1992) Elements of structural optimization. Kluwer Academic Publishers, Dordrecht.

Haug, E.J. and Arora, J.S. (1979) Applied optimal design. John Wiley \& Sons, New York.

Hsieh, C.C and Arora, J.S. (1984) Design sensitivity analysis and optimization of dynamic response, Computer Methods in Applied Mechanics and Engineering, 43, pp. 195-219.

Samtech (1994) Samcef Mecano version 5.1. Liège.

Sohoni, V.N. and Haug, E.J. (1982) A state space technique for optimal design of mechanisms, ASME Journal of Mechanical Design, 104, pp. 792-798.

Vanderplaats, G.N. (1993) Thirty years of modern structural optimization, Advances in Engineering Software, 16, pp. 81-88. 